\title{
Youth Not in Education, Employment and Training (NEET) in Sri Lanka
}

\author{
Naveen Wickremeratne*, Priyanga Dunusinghe \\ Department of Economics, University of Colombo, Sri Lanka
}

\begin{abstract}
Copyright $\subseteq 2018$ by authors, all rights reserved. Authors agree that this article remains permanently open access under
\end{abstract} the terms of the Creative Commons Attribution License 4.0 International License

\begin{abstract}
This study attempts to investigate the Youth Not in Education, Employment and Training (NEET) in Sri Lanka. The objectives of this study include identifying the share of youth NEET in Sri Lanka as a percentage of population with regards to national, sectoral, gender, education, ethnicity and marital status, and to identify the determinants of those who are NEET. This study is based on cross-sectional data obtained from Sri Lanka Labour Force Survey (SLFS) 2015. The methodology adopted for the study consists of two major components. First component attempts to generate youth NEET estimates for Sri Lanka using descriptive statistics tools. The second component of the methodology includes a logistic regression analysis to identify the determinants of youth NEET. The study found that Sri Lanka has a significantly high youth NEET rate of 25.8 percent in 2015, which is unsatisfactory to the Sri Lankan labour market. This raises the labour market vulnerability with regards to youth population of Sri Lanka. The research also found the significant NEET disparities among youths by sector, gender, age, education, ethnicity and marital status. Moreover, the logistic regression analysis identified age, gender, education, residential sector and marital status as the significant determinants of youth NEET in Sri Lanka.
\end{abstract}

Keywords Sri Lanka, Youth NEET

\section{Introduction}

The youth unemployment rate provides only a mere information regarding the existing labour market situation of young people.[1] Unemployment in general can be defined as "Persons available and/or looking for work, and who did not work and taken steps to find a job during last four weeks and ready to accept a job given a work opportunity within next two weeks".[2] This definition, which interprets unemployment very narrowly, can underestimate the extent of the problem in particular with respect to young people. Therefore, youth unemployment should be enhanced with a focus on youth NEET. SLFS report considers youth NEET rate as an essential measure as it considers all young people in the age group of 15 24 years, who are not employed, not in the labour force and also not in the education or training. Thus, NEET rate provides a wider understanding about the youth labour market in Sri Lanka.

Though Elder [3] identified "NEET rate" as a novel indicator, the original concept of NEET was first used in a report titled "Bridging the Gap: New Opportunities for 16 - 18 Year Olds Not in Employment, Education or Training”, [4] in the United Kingdom (UK). However, currently the concept of youth NEET has been granted a greater importance by international institutions such as International Labour Office (ILO) and United Nations (UN), due to its presupposed promise to address a wider range of youth vulnerabilities, such as youth unemployment, early school dropouts and labour market discouragement.

In Sri Lanka, unemployment rate takes a low value of $4.7 \%$ in 2015. However, youth unemployment rate is significantly high at $20.8 \%$ in 2015 . Thus, Sri Lanka is currently facing a greater challenge of reducing the youth unemployment rate. Yet, reducing youth unemployment rate to a favourable level does not necessarily get Sri Lanka out of the vulnerability in labour market, since youth unemployment rate does not include youth NEET component of 25.8\%.[2] Higher NEET rate indicates a higher vulnerability with respect to youth population in Sri Lanka. At this backdrop, it is very much prudent to estimate youth NEET rates under various conditions, and the root causes and determinants of such high rates in Sri Lanka.

\section{Literature Review}

There exist a limited number of international literatures focussing on youth NEET, given the novelty of this topic in the labour economics literature. Most of these studies emphasise the adverse effects of becoming NEET and the 
determinants of being NEET.

Furlong [5] investigated youth NEET, focusing on problematic labour market transitions among early school-leavers of Scotland. The findings of the study suggested that an alternative and powerful conceptualization of NEET is needed, which attempts to capture the long-term experience of NEET. The study revealed that youths who are highly educated with well positioned parents were less likely to become NEET. Further, there was a less likelihood of becoming NEET among youths with their own houses than youths resided in social inclusion partnership houses.

Yuji [6] conducted a study on "Jobless Youths and the NEET Problem in Japan". In this study, he tried to examine the determinants of non-employed young Japanese people, giving more emphasis on youth NEET in Japan during 1990 to 2000. The study was based on secondary data obtained from the Employment Status Survey and the methodology adopted was Multinomial Logistic Regression Model. The findings of this study reveal that the probability of becoming NEET in the age category of 15 to 34 years is high. Moreover, NEETs include less educated, low work experience and those from poor families. Further, the marginal effects of the Logistic Regression identified that educational attainment has a strong effect on whether one will look for a job or want to work in the Japanese labour market.

McGuinness and Kelly [7] studied the impact of the recession on the structure and labour market success of NEET youth in Ireland. Secondary data of Quarterly National Household Survey of Ireland, through a binary probit model, is used to identify the characteristics associated with being a NEET youth and being an unemployed prime-aged individual in both 2006 and 2011. Results of the model found that there is a greater tendency among females to become NEET as compared to males, while age group of 20 - 24 including both males and females indicated a likelihood of becoming NEET in comparison to the age group of 15 - 19. Further, educational attainment and geographic location were highly significant in determining the youth NEET in Ireland.

Kovrova and Lyon [8] investigated the NEET youth dynamics in Indonesia and Brazil through a cohort analysis. The study found that both countries have seen a slight but steady downward trend in NEET youth since the middle of the decade beginning from 2000, interrupted only in Brazil during the 2008 - 2009 global economic crisis. Yet, the study pinpointed that NEET youth nonetheless remains as an important policy concern in both countries, accounting for $23 \%$ of all Brazilian youth in 2009 and for $28 \%$ of all Indonesian youth in 2010. Both descriptive and econometric evidence for the two countries claims an improving situation for female youth in particular where they are less likely to be absent from both education and the labour force than males. More importantly, educational attainment acts as a major determinant of NEET status in both Indonesia and Brazil.

Ranzani and Rosati [9] carried out a dynamic analysis regarding the NEET trap in Mexico. This study attempts to assess whether NEET status is persistent and to what extent it affects future employment perspectives. This study uses quarterly data from the Mexican labour force surveys from 2000 to 2004, and the methodology adopted for the study was a dynamic multinomial logit panel data model with random effects. The model estimate revealed that being NEET seems to be a trap for youth at least in the medium run especially for poor, less educated youth and for women in Mexico.

Bacher et al, [1] investigated the causes and characteristics of NEET youth and exit strategies in Austria. This research examined the questions of how many young people in Austria have been affected by NEET status, which socio-structural characteristics they display, and what causes an increased NEET risk. Moreover, this study has focused on the decisive factors as an exit strategy from NEET. The methodology adopted for the study indicates the elements of both qualitative and quantitative approaches from 2006 to 2012. Linear regression and explorative path models adopted by Alwin and Hauser in 1975 were applied for quantitative data analysis. Findings proclaimed on average about 78,000 young people in Austria, aged between 16 and 24 were NEET. Furthermore, NEET risk is higher in early school leavers, specifically for female youths with care duties. Moreover, there is a greater risk of being NEET among youths who live in urban areas.

Samoilenko and Carter [10] investigated the economic outcomes of youth NEET up to four years after the initial period of NEET in New Zealand. This study covered the outcomes of NEETs in relation to benefit receipt, education, employment and future inactivity, by intending to compare these outcomes across NEETs and a control group of non-NEETs. This study was based on the data obtained from the Survey of Family, Income and Employment (SoFIE) by Statistics New Zealand, covering the period from 2002 to 2010. Methodology adopted for the study included Propensity Score Matching (PSM) developed by Rosenbaum and Rubin in 1983 to control for observed characteristics of NEETs. The findings proclaimed that individuals associated with a long period of NEET in their youth achieve relatively poorer outcomes than their control group peers after the first two years. Further, the study revealed that long-term NEETs are less likely to be employed and more likely to be inactive and/or receiving a benefit.

Feng et al, [11] studied the consequences, risk factors and geography of NEET young people in Scotland over the past two decades. They incorporated the Scottish Longitudinal Study (SLS), which included the census data for the period from 1991 to 2001. A logistic regression approach was utilised to investigate the relationship between the dependent variable, being NEET or not, and 
explanatory variables such as gender, age, educational attainment etc. The results found that less educated youth are more likely to become NEET, so as the youths with poor physical health. More importantly, they identified a scarring effect in economic activity which raises the tendency of becoming NEET. Moreover, findings of the study divulged that being NEET is associated with several demographic and socioeconomic factors such as gender, geographic location and family environment.

Mendolia and Walker [12] examined the relationship between personality traits in adolescence and education and labour market choices, giving more emphasis on youth NEET. In this study, impact of locus of control, effort and diligence and self-esteem were identified as major personality traits. This study incorporated secondary data from the Longitudinal Study of Young People in England (LSYPE). The study found that personality traits have a significant relationship with the probability of being NEET between the ages of 18 and 21. According to the authors, this relationship has a greater significance than the child's and family's characteristics in determining the NEET status.

Susan li [13] researched the NEET in Turkey, incorporating two purposes in to the study. Firstly, to examine the determinants of the NEET status for the Turkish youth since Turkey has the highest NEET rate among the Organisation for Economic Co-operation and Development (OECD) countries. Secondly, describe the movement of the youth across four states, such as education, employment, unemployment and inactivity. Findings of the study revealed that higher levels of education and a greater number of household members in employment are associated with a significantly lower likelihood of being NEET and this is more favourable for women population in Turkey. However, the findings of the probit estimate suggested that marriage or having a child will raise the likelihood of becoming NEET for women.

Predominantly, all most all the studies conducted in the direction of "Youth NEET" attempted to investigate the country specific NEET estimates based on local surveys. In this context majority of the literature has provided more focus on determinants of becoming a NEET. However, there exists a significant vacuum in literature on youth NEET and determinants of youth NEET in Sri Lanka. In this backdrop, this study attempts to rectify that inattention by fulfilling the vacuum in this direction of Labour Economics literature.

\section{Rationale of the Research}

There exists a greater vacuum of literature in Sri Lanka with respect to the studies focusing on "Youth NEET". Yet, the significance of the research title has been highly validated by the international academia. Moreover, despite having a considerably high unemployment rate in Sri
Lanka, youth NEET rate also has skyrocketed by increasing the vulnerability of the Sri Lankan youth labour market. In this context, this study attempts to fill up this vacuum of local literature, by facilitating empirically grounded insights of youth NEET in Sri Lanka. Further, the study aims to provide evidence-based policy recommendations with the potential of influencing the national level policy formulation to reduce vulnerability among Sri Lankan youth.

\section{Problem Statement}

Youth unemployment has been replaced with a focus on youth NEET. With current level of high national youth NEET rate in Sri Lanka, this emphasis helps us to identify whether the national youth NEET rate has any disparities, given the provincial, district, urban and rural levels, incorporating gender, education, ethnicity, religion and marital status. Further, this study attempts to address the question of what determines youth NEET in Sri Lanka.

\section{Objectives}

There are four specific objectives in this study:

- To identify the share of youth NEET in Sri Lanka as a percentage of population with regards to national, provincial, district, urban, rural levels, and gender, education, ethnicity, religion and marital status.

- To identify the determinants of those who are NEET.

- To identify the vulnerability caused by the youth NEET in Sri Lankan labour market.

- To identify the feasible policy recommendations to reduce the share of youth NEET in Sri Lanka.

\section{Source of Data}

The study is entirely based on cross-sectional data obtained from SLFS conducted by Department of Census and Statistics (DCS), Sri Lanka. SLFS intends to measure the levels and trends of employment, unemployment and labour force in Sri Lanka on a continuous basis.[2] SLFS has adopted two stage stratified sampling method to determine the sample of 25,000 housing units including 82,800 individuals enumerated by the survey. This survey also provides national, provincial and district level estimates, focusing on literacy, household economic activities, informal sector employment and underemployment. SLFS data set includes 82,800 observations with 117 variables to measure the levels and trends of employment, unemployment and labour force. Thus, in this study these 82,800 observations were entirely selected to generate NEET statistics for Sri Lanka. However, based on the conceptualization and the definition of youth NEET in Sri Lanka, 11,708 observations were 
selected to derive the empirical econometrics model for the study.

\section{General Methodology}

Methodology adopted for the study consists of two major components. First component attempts to generate youth NEET estimates for Sri Lanka, using descriptive statistics tools and Stata statistical software programming. This section of the methodology generates national, sectoral and district level youth NEET estimates, categorizing them by gender, age, education, ethnicity, religion and marital status of Sri Lankan population. The second component of the methodology includes an empirical econometric model in order to investigate the determinants of youth NEET in Sri Lanka.

\section{Empirical Model}

Discrete choice models, such as the logit model, explain the responses of individuals by analysing their decision process. They are useful in situations in which the dependent variable is categorical, with dichotomous or fictitious cases being very common. The logit model is similar to the probit model. Logit model uses a logistic type cumulative distribution function and probit model uses a normal distribution function.[14] Logit model coefficients do not coincide with the derivative of the function with respect to the corresponding variable. The interpretation of these coefficients is not similar to that of the linear regression model. However, it can be used to interpret the ratios of parameters associated with each of the independent variables that define the model. Besides, the independent or explanatory variables of the individual response or choice may be quantitative or qualitative.

Logit model has been employed to explore the significant determinants of youth NEET in Sri Lanka. The rationale for employing a logistic regression analysis for the study is justified owing to the fact that logistic regression is a statistical technique that allows you to investigate the relationship between an outcome variable (e.g., being NEET or not) and various explanatory variables.[11] The analysis identifies which of the explanatory variables is significantly and independently related to the outcome variable. In this research, the dependent variable $\mathrm{Y}$ is a dichotomous variable indicating whether the individual is NEET or not. Hence the functional form equation can be expressed as,

$$
\begin{aligned}
& Y_{i}=\beta o+\Sigma_{\mathrm{j}=1}^{\mathrm{k}} \beta_{j} x_{i j}+\varepsilon_{i} \\
& \begin{aligned}
P(\text { if } Y=1 \mid X) & \text { (1) description of explanatory variables is as follows. } \\
& =\beta o+\beta_{1} \text { Age }+\beta_{2 i} \Sigma_{j=1}^{2} \text { Gend }+\beta_{3 i} \Sigma_{j=1}^{3} R S+\beta_{4 i} \Sigma_{j=1}^{6} E d u+\beta_{5 i} \Sigma_{j=1}^{7} E \text { th } \\
& +\beta_{6 i} \Sigma_{j=1}^{4} \text { Reli }+\beta_{7 i} \Sigma_{j=1}^{5} M S
\end{aligned}
\end{aligned}
$$

Where $Y_{i}$ is not observed, it is considered as a latent variable, thus a binomial variable is observed. $Y_{i}$ can be defined as,

$$
\begin{gathered}
Y_{i}=1 \text { (if the individual is considered as NEET) } \\
Y_{i}=0 \text { (if the individual is not considered as NEET) }
\end{gathered}
$$

The logit model allows the adjustment and calculation of the probability $\left(\mathrm{P}_{\mathrm{i}}\right)$ of the individual, depending on the set of explanatory variables, belonging to one of the two groups specified in the dependent variable $\left(\mathrm{Y}_{\mathrm{i}}\right)$. These probabilities are given by,

$$
\begin{gathered}
\text { If } Y_{i}=1 \\
P_{i}(y=1 \mid X \\
P_{i}\left(\text { if } Y_{i}=1, \text { probability of occuring } Y\right) \\
\begin{array}{c}
\text { If } Y_{i}=0 \\
1+e^{-z}
\end{array}=\frac{e^{z}}{1+e^{z}} \text { (Logistic Distribution Function } \\
P_{i}(y=0 \mid X)=1-P_{i}\left(\text { if } Y_{i}=\right. \\
=0, \text { probability of occuring } Y) \\
1-P_{i}=1-\frac{e^{z}}{1+e^{-z}}= \\
\frac{1}{1+e^{z}}(\text { Logistic Distribution Function })
\end{gathered}
$$

The above logistic distribution function can be rearranged as,

$$
\frac{P_{i}}{1-P_{i}}=\frac{1+e^{z}}{1+e^{-z}}=e^{z}
$$

In the equation (6), $\mathrm{z}$ can be expressed as,

$$
Z_{i}=\beta o+\beta_{1} X_{1}+\cdots+\beta_{k} X_{1 k}
$$

In the equation (6), $\mathrm{Pi} /(1-\mathrm{Pi})$ is simply the odds ratio in favour of occurring $\mathrm{Y}$ (being NEET in this context). Odds ratio is the ratio of the probability that an individual will be a NEET to the probability that he or she will not be a NEET. Hence, odds ratio can be written as,

$$
\frac{P(\text { The youth is a NEET })}{P(\text { The youth is not a NEET })}
$$

By taking the natural log of equation (6), following equation can be derived.

$$
L_{i}=\ln \left(\frac{p_{i}}{1-p_{i}}\right)=Z_{i}=\beta o+\beta_{1} X_{1}+\cdots+\beta_{k} X_{1 k}
$$

In this model, $\mathrm{i}$ stand for individuals and $\mathrm{j}$ stands for number of dummies. $\mathrm{Y}$ is the dichotomous dependent variable and $\mathrm{X}$ is the vector of explanatory variables. The 
Table 1. Description of Explanatory Variables

\begin{tabular}{|c|c|}
\hline Variable & Description \\
\hline \multicolumn{2}{|l|}{ Individual Characteristics } \\
\hline Age (AGE) & Individual's age in number of years \\
\hline Gend (GENDER) & Individuals gender (1=Male, 2=Female) \\
\hline RS (RESIDENTIAL SECTOR) & Individuals residential sector (1=Urban, 2=Rural, 3=Estate) \\
\hline Edu (EDUCATION) & $\begin{array}{l}\text { Individual's level of education (1=Up to Grade } 5 \text { and Below, } 2=\text { Grade 6-10, 3=G.C.E. O/L, 4=G.C.E. } \\
\text { A/L, } 5=\text { Degree and Above, } 6=\text { No Schooling) }\end{array}$ \\
\hline Eth (ETHNICITY) & $\begin{array}{c}\text { Ethnicity of the individual (1=Sinhalese, 2=Sri Lankan Tamil, 3=Indian Tamil, 4=Sri Lankan Moor, 5= } \\
\text { Malay, 6=Burger, 7=Other) }\end{array}$ \\
\hline Reli (RELIGION) & Individual’s religion (1=Buddhist, 2=Hindu, 3=Islam, 4=Catholic) \\
\hline MS (MARITIAL STATUS) & Individual's marital status (1=Never Married, 2=Married, 3=Widowed, 4=Divorced, 5=Separated) \\
\hline
\end{tabular}

Source: Author

\section{Results and Discussion}

As reported in Table 2, there are 734,550 "NEET" youngsters in Sri Lanka. This amount of population claims that $25.8 \%$ of Sri Lankan youth who are in the age group of 15 - 24 are NEET. This show that approximately one out of every four youths belongs to the NEET group. In contrast, this figure demonstrates the vulnerability of Sri Lankan labour market with respect to youths, since these youths have not been empowered, either to engage in an employment or human development opportunity such as learning or vocational training.

Table 2. Youth NEET in 2015

\begin{tabular}{|lccc|}
\hline & $\begin{array}{c}\text { NEET } \\
\text { Population }\end{array}$ & $\begin{array}{c}\text { Youth } \\
\text { Population }\end{array}$ & NEET Rate \\
\hline Total & 734550.5 & 2847086 & $\mathbf{2 5 . 8 0 \%}$ \\
Male & 224501.4 & 1374959 & $\mathbf{1 6 . 3 3 \%}$ \\
Female & 510049.1 & 1472127 & $\mathbf{3 4 . 6 5 \%}$ \\
\hline \multicolumn{4}{l}{ Source: Author's estimates based on SLFS (2015) Data. } \\
\hline
\end{tabular}

Further by gender, there are 224,501 males and 510,049 females in NEET status, indicating $16.33 \%$ and $34.65 \%$ respectively as percentages. In contrast, this indicates that female NEET is higher than male NEET. Usually in the Sri Lankan context, after achieving a specific level of education, young women tend to remain at houses without pursuing further studies or engaging in labour market. According to Perera, [16] in Sri Lanka, there exists a protectionist legislature, limiting the women's access to vocational training as well as social and cultural norms barricade in determining women's inclusion in the labour market. Thus, lack of young female engagement in labour market, education and training creates a destructive path in regard to future labour market, thereby obstructing the sustainable and inclusive growth momentum in Sri Lanka.

As indicated by Table 3, the sectoral disparities in youth NEET in Sri Lanka, urban sector records the lowest youth NEET rate of $22 \%$ while estate sector records the highest of $32 \%$. Rural sector being the largest residential sector, records a moderate rate of $26 \%$. In Sri Lanka, estate sector has very poor educational infrastructure and labour market opportunities in comparison to both urban and rural sectors. Thus, it can be the major root cause for having such a high NEET rate. However, lowest NEET rate recorded from urban sector can be justified due to the availability of developed infrastructure facilities, well established educational and labour market opportunities.

According to Table 4 and 5, the highest NEET rate of $31.78 \%$ is recorded from Eastern province while the lowest recorded is $20.67 \%$ from Western province, which validates the trend observed in sectoral youth NEET disparities. Colombo district has the lowest youth NEET rate of $18.86 \%$ while Trincomalee has the highest of $33.77 \%$. As we analyze the youth NEET rates by district, in general, more urbanized districts have recorded relatively lower NEET rates and the same rationale noticed in the sectoral disparities of youth NEET can be applied to this instance. Yet, surprisingly, Vavunia, being a very rural district in Sri Lanka, recorded the $3^{\text {rd }}$ lowest youth NEET rate of $20.63 \%$.

Table 3. Youth NEET in Sri Lanka by Sector in 2015

\begin{tabular}{|lccc|}
\hline Sector & NEET Population & Youth Population & NEET Rate \\
\hline Urban & 108210.8 & 491174.8 & $\mathbf{2 2 . 0 3 \%}$ \\
Rural & 590488.8 & 2243901.0 & $\mathbf{2 6 . 3 2 \%}$ \\
Estate & 35850.99 & 112010.3 & $\mathbf{3 2 . 0 1 \%}$ \\
\hline Source: Author's estimates based on SLFS (2015) Data. & \\
\hline
\end{tabular}

Table 4. Youth NEET in Sri Lanka by Province in 2015 


\begin{tabular}{|lccc|}
\hline \hline Province & NEET Population & Youth Population & NEET Rate \\
\hline Western Province & 161687.50 & 782101.80 & $\mathbf{2 0 . 6 7 \%}$ \\
Central Province & 88811.49 & 341801.80 & $\mathbf{2 5 . 9 8 \%}$ \\
Southern Province & 89302.91 & 338802.20 & $\mathbf{2 6 . 3 6 \%}$ \\
Northern Province & 47527.13 & 186994.10 & $\mathbf{2 5 . 4 2 \%}$ \\
Eastern Province & 86855.50 & 273271.20 & $\mathbf{3 1 . 7 8 \%}$ \\
North Western Province & 77631.30 & 307715.70 & $\mathbf{2 5 . 2 3 \%}$ \\
North Central Province & 47969.49 & 168016.20 & $\mathbf{2 8 . 5 5 \%}$ \\
Uva Province & 57364.24 & 188716.50 & $\mathbf{3 0 . 4 0 \%}$ \\
Sabaragamuwa Province & 77400.91 & 259666.80 & $\mathbf{2 9 . 8 1 \%}$ \\
\hline Source: Author's estimates based on SLFS (2015) Data. \\
\hline
\end{tabular}

Table 5. Youth NEET rates by District in 2015

\begin{tabular}{|lccc|}
\hline District & Population & Population & Rate \\
\hline Colombo & 57296.80 & 303816.00 & $\mathbf{1 8 . 8 6 \%}$ \\
Gampaha & 70099.52 & 309990.70 & $\mathbf{2 2 . 6 1 \%}$ \\
Kalutara & 34291.18 & 168295.10 & $\mathbf{2 0 . 3 8 \%}$ \\
Kandy & 48374.05 & 198332.40 & $\mathbf{2 4 . 3 9 \%}$ \\
Matale & 15795.95 & 59410.05 & $\mathbf{2 6 . 5 9 \%}$ \\
Nuwara Eliya & 24641.49 & 84059.31 & $\mathbf{2 9 . 3 1 \%}$ \\
Galle & 38936.48 & 142791.80 & $\mathbf{2 7 . 2 7 \%}$ \\
Matara & 28877.17 & 115631.50 & $\mathbf{2 4 . 9 7 \%}$ \\
Hambantota & 21489.26 & 80378.88 & $\mathbf{2 6 . 7 3 \%}$ \\
Jaffna & 25471.97 & 103019.60 & $\mathbf{2 4 . 7 3 \%}$ \\
Mannar & 5014.49 & 18711.71 & $\mathbf{2 6 . 8 0 \%}$ \\
Vavunia & 5450.52 & 26423.63 & $\mathbf{2 0 . 6 3 \%}$ \\
Mullaitivu & 5945.29 & 20455.16 & $\mathbf{2 9 . 0 6 \%}$ \\
Kilinochchi & 5644.87 & 18384.03 & $\mathbf{3 0 . 7 1 \%}$ \\
Batticaloa & 26488.75 & 90387.16 & $\mathbf{2 9 . 3 1 \%}$ \\
Ampara & 35796.80 & 110134.90 & $\mathbf{3 2 . 5 0 \%}$ \\
Trincomalee & 24569.94 & 72749.05 & $\mathbf{3 3 . 7 7 \%}$ \\
Kurunegala & 47532.60 & 199612.20 & $\mathbf{2 3 . 8 1 \%}$ \\
Puttalam & 30098.70 & 108103.60 & $\mathbf{2 7 . 8 4 \%}$ \\
Anuradhapura & 33827.53 & 119239.20 & $\mathbf{2 8 . 3 7 \%}$ \\
Polonnaruwa & 14141.96 & 48777.02 & $\mathbf{2 8 . 9 9 \%}$ \\
Badulla & 37309.18 & 119673.90 & $\mathbf{3 1 . 1 8 \%}$ \\
Moneragala & 20055.06 & 69042.70 & $\mathbf{2 9 . 0 5 \%}$ \\
Ratnapura & 46831.23 & 150720.70 & $\mathbf{3 1 . 0 7 \%}$ \\
Kegalle & 30569.67 & 108946.10 & $\mathbf{2 8 . 0 6 \%}$ \\
\hline Source: Author's estimates based on SLFS $(2015)$ Data. & \\
\hline
\end{tabular}

In definition, youth NEET is calculated for the age group of 15 - 24 years. So that, it is very much prudent to investigate the youth NEET rate by age. There are disparities of youth NEET as age differs within the respective age group. As indicated by Table 6 , the lowest youth NEET rate of $4.86 \%$ is reported from the age of 15 years, while the highest of $38.93 \%$ is reported from the age of 21 years. However, on average, there is an upward trend of youth NEET, exhibiting that youth NEET rises as the age increases within the considered age group.

Table 7 records Youth NEET in Sri Lanka by educational attainment. The highest youth NEET rate of $81.38 \%$ is reported from the youths who have never received a school education in their lives, while the lowest of $21.37 \%$ is reported from the youths who have studied up to Ordinary Level of General Certificate of Education (G.C.E. O/L) in Sri Lanka. More importantly, there exists a U-shaped curve of youth NEET by the level of education. The youth NEET rate is high at lower level of education as well as at higher level of education. It is very much obvious that youth NEET rate is high among unschooled due to lack of literacy and potential leading to dearth of labour market and further education and training opportunities. Yet, it is a surprising result that youth NEET rate is high among youths who are at the highest education level in Sri Lanka. In contrast, this phenomenon adversely affects the future of Sri Lankan labour market since, youth NEET is high among the population who have achieved a higher level of human development. 
Table 6. Youth NEET in Sri Lanka by Age in 2015

\begin{tabular}{|cccc|}
\hline Age & NEET Population & Population & NEET Rate \\
\hline $\mathbf{1 5}$ & 16774.02 & 344991.30 & $\mathbf{4 . 8 6 \%}$ \\
$\mathbf{1 6}$ & 31332.46 & 310530.60 & $\mathbf{1 0 . 0 9 \%}$ \\
$\mathbf{1 7}$ & 54270.71 & 291688.10 & $\mathbf{1 8 . 6 1 \%}$ \\
$\mathbf{1 8}$ & 61756.49 & 298142.00 & $\mathbf{2 0 . 7 1 \%}$ \\
$\mathbf{1 9}$ & 83295.48 & 290842.20 & $\mathbf{2 8 . 6 4 \%}$ \\
$\mathbf{2 0}$ & 102579.40 & 288729.70 & $\mathbf{3 5 . 5 3 \%}$ \\
$\mathbf{2 1}$ & 104808.30 & 269196.90 & $\mathbf{3 8 . 9 3 \%}$ \\
$\mathbf{2 2}$ & 91783.80 & 249954.10 & $\mathbf{3 6 . 7 2 \%}$ \\
$\mathbf{2 3}$ & 86047.55 & 239579.80 & $\mathbf{3 5 . 9 2 \%}$ \\
$\mathbf{2 4}$ & 101902.30 & 263431.60 & $\mathbf{3 8 . 6 8 \%}$ \\
\hline Source: Author's estimates based on SLFS (2015) Data. \\
\hline
\end{tabular}

Table 7. Youth NEET in Sri Lanka by Educational Attainment in 2015

\begin{tabular}{|lccc|}
\hline Level of Education & NEET Population & Youth Population & NEET Rate \\
\hline No Schooling & 10266.64 & 12616.01 & $\mathbf{8 1 . 3 8 \%}$ \\
Grade 5 \& Below & 19100.55 & 44511.63 & $\mathbf{4 2 . 9 1 \%}$ \\
Grade 6-10 & 374292.80 & 1382489.00 & $\mathbf{2 7 . 0 7 \%}$ \\
G.C.E. (O/L) & 105376.50 & 493136.00 & $\mathbf{2 1 . 3 7 \%}$ \\
G.C.E.(A/L) & 219770.00 & 898391.30 & $\mathbf{2 4 . 4 6 \%}$ \\
Degree and Above & 4426.07 & 13254.27 & $\mathbf{3 3 . 3 9 \%}$ \\
\hline Source: Author's estimates based on SLFS (2015) Data. \\
\hline
\end{tabular}

Table 8, 9 and 10 indicate Youth NEET in Sri Lanka by marital status, ethnic group and religion. Regarding the youth NEET rate by marital status of the individual, the highest rates are recorded from the youths who are married and widowed indicating rates of $60.41 \%$ and $61.26 \%$ respectively. However, the lowest youth NEET rate which is $19.96 \%$ is recorded from the youth who have never married. The lowest youth NEET rate of $11.92 \%$ is recorded from Burger youths while the highest youth NEET rate of 33.3\% exists among Sri Lankan Moor ${ }^{1}$ population. This is an apparent phenomenon owing to the fact that some Muslim cultural norms act as barriers for Muslim women in participating in educational, training and labour market opportunities. Since youth NEET rate is generally high among females, it can be presumed that same trend applies to the Muslim population in Sri Lanka. The highest youth NEET rate of 32.93\% is reported from the Islamic youths while the lowest of $24.38 \%$ is reported from Buddhist youths in Sri Lanka.

Table 8. Youth NEET in Sri Lanka by Marital Status in 2015

\begin{tabular}{|lccc|}
\hline Maritial Status & NEET Population & Youth Population & NEET Rate \\
\hline Never Married & 485161.10 & 2430616.00 & $\mathbf{1 9 . 9 6 \%}$ \\
Married & 243707.00 & 403408.30 & $\mathbf{6 0 . 4 1 \%}$ \\
Widowed & 2464.01 & 4022.19 & $\mathbf{6 1 . 2 6 \%}$ \\
Divorced & 1020.92 & 2267.93 & $\mathbf{4 5 . 0 2 \%}$ \\
Seperated & 2197.50 & 6771.59 & $\mathbf{3 2 . 4 5 \%}$ \\
\hline Source: Author's estimates based on SLFS (2015) Data. \\
\hline
\end{tabular}

Table 9. Youth NEET in Sri Lanka by Ethnic Group in 2015

\begin{tabular}{|lccc|}
\hline Ethnic Group & NEET Population & Youth Population & NEET Rate \\
\hline Sinhala & 485270.7 & 2004234 & $\mathbf{2 4 . 2 1 \%}$ \\
Sri Lankan Tamil & 95544.1 & 368281.3 & $\mathbf{2 5 . 9 4 \%}$ \\
Indian Tamil & 35426.95 & 113057.8 & $\mathbf{3 1 . 3 4 \%}$ \\
Sri Lankan Moor & 115900.5 & 348030.2 & $\mathbf{3 3 . 3 0 \%}$ \\
Malay & 1731.097 & 8421.928 & $\mathbf{2 0 . 5 5 \%}$ \\
Burger & 483.2798 & 4055.385 & $\mathbf{1 1 . 9 2 \%}$ \\
Other & 193.8388 & 1005.227 & $\mathbf{1 9 . 2 8 \%}$ \\
\hline Source: Author's estimates based on SLFS (2015) Data. \\
\hline
\end{tabular}

1 The term Moors refers to the Muslim inhabitants of the Maghreb, North Africa, the Iberian Peninsula, Sicily, and Malta. 
Table 10. Youth NEET in Sri Lanka by Religion in 2015

\begin{tabular}{|lccc|}
\hline Religion & NEET Population & Youth Population & NEET Rate \\
\hline Buddhist & 453888.2 & 1861588 & $\mathbf{2 4 . 3 8 \%}$ \\
Hindu & 106582.2 & 395558.6 & $\mathbf{2 6 . 9 4 \%}$ \\
Islam & 116384.8 & 353405.9 & $\mathbf{3 2 . 9 3 \%}$ \\
Catholic \& Christians & 57695.26 & 236069.3 & $\mathbf{2 4 . 4 4 \%}$ \\
\hline Source: Author's estimates based on SLFS (2015) Data. \\
\hline
\end{tabular}

\section{Logistic Regression Results ${ }^{2}$}

Given that the logistic regression coefficients are difficult to interpret due to the nature of coefficient estimation through the model, odds ratios provide a readily interpretable and easily estimated compromise.[17] The entire three models are statistically significant at $1 \%$ level since (Prob > chi2) is less than 0.01. Logistic regression models are fitted using the method of maximum likelihood, so instead of R-squared in linear regression model, Pseudo R-squared can be seen in logistic regression output.[18] In the third model which has the highest Pseudo R-squared of 0.153 explains that $15.3 \%$ of the variability of the dichotomous dependent variable $(\mathrm{NEET}=1$ or NOT-NEET $=0$ ) is jointly explained by the independent variables.

There is a positive relationship between the age of the individual and that individual's likelihood of becoming a NEET. Thus, this positive relationship is statistically significant at $1 \%$ level. Age has a coefficient value of 0.195 in the final model, explaining that log odds of becoming youth NEET increased by 0.195 for each one-year increase in age among the youths who are at the age group of $15-24$. As odds ratios are analyzed, age has an odds ratio of 1.214, meaning that the youth at a given level of age is 1.21 times more likely to become NEET than a youth who is one year younger. In other words, one-year increase in age increases the odds of becoming NEET by $21 \%$. Moreover, in developed countries also an identical relationship can be noticed. Hence, an increase in age increases the likelihood of being NEET, since younger persons take advantage of job opportunities better than older persons.[6]

There observed a positive and significant relationship between becoming NEET and being a female youth in the respective age group. Female youths have a 0.987 coefficient value considering male youths as the base category. This indicates that log odds of becoming youth NEET increased by 0.987 for a female compared to a male. Further, females have an odds ratio of 2.68, explaining that a female is 2.68 times more likely to become a youth NEET compared to a male in Sri Lanka. Hence, young women are more likely to be NEET than young men. This is not only valid for Sri Lanka, since this result is consistent all over

2 Please refer the Appendix Table 11 and 12 for Regression Output Tables the world amongst 18 - 24 year olds. There are more young women who are NEET than young men and this has been consistently the case for at least the last decade.[18] Despite the fact that most of the literature in this direction has not addressed the issue of why there are so many NEET young women, Feng et al, [11] identified a traditional explanation which is that young women are given more caring responsibilities than that of males.

In the attempt of investigating the linkage between a youth being a NEET and the level of education, no schooling category has been employed as the reference category in the logistic regression analysis. In that context, all the other educational levels have demonstrated negative, significant coefficients in comparison to the reference category of no schooling. Firstly, log odds of becoming NEET decreased by 2.28 for the youths who have attained an education level up to Grade 5 or below compared to youths with no schooling. According to log odds ratio, youths with an education level of Grade 5 or below compared to youths with no schooling, decreases the odds of becoming NEET by $89.8 \%$ (1 - 0.102). Secondly, log odds of becoming NEET decreased by 2.79 for the youths who have attained an education level of Grade 6 to 10, compared to youths with no schooling. In other words, youths with an education level of Grade 6 to 10, compared to youths with no schooling, reduces the likelihood of becoming NEET by $93.8 \%(1-0.061)$. Thirdly, log odds of becoming NEET decreased by 3.17 for the youths who have attained an education level up to G.C.E. O/L in comparison to the youths with no schooling. Thus, the probability of becoming NEET is decreased by $95.9 \%$ with regard to youths attained an education level up to G.C.E. O/L, compared to youths with no schooling.

Fourthly, in relate to the youths with an education level up to Advance Level of General Certificate of Education (G.C.E. A/L), compared to youths with no schooling, the log odds of being a youth NEET is reduced by 3.25. Hence, this suggests that youths with an education level up to G.C.E. A/L, compared to youths with no schooling, decreases the odds of being a NEET by $96.2 \%(1-0.038)$. Finally, youths with the highest level of educational attainment which is degree and above, tend to lessen the log odds by 3.36, in comparison to youths with no education. However, youths who attained the highest level of education have only been able to reduce the likelihood 
of becoming NEET by $65.6 \%(1-0.344)$ compared to youths with no schooling. This fact again validates the finding of U-shaped youth NEET rate curve in Sri Lanka in relation to level of education. Thus, the likelihood of becoming youth NEET increases at both lower and upper level of education, reckoning the vulnerability of educated youth in Sri Lanka.

In the third model, only Sri Lankan Tamil youths have indicated a positive and significant impact on being NEET, given the fact that Sinhalese youths are considered as the reference ethnic group. The coefficient value, given for Sri Lankan Tamils is 0.25 . This explains that being a Sri Lankan Tamil increases the log odds by 0.25 . Hence, being a Sri Lankan Tamil increases the likelihood of becoming a youth NEET by $29.6 \%$, given Sinhalese youths as the reference ethnic group. However, all the other ethnic groups do not indicate any significant linkages with the NEET status. Besides, all the religions in Sri Lanka are statistically insignificant in determining whether the particular youth is a NEET or not. That concludes the fact that religion status of the youth does not determine the NEET status in Sri Lanka.

Susan li [13] emphasized the validity of marital status in determining the youth NEET status, owing to the fact that marriage raises the responsibility of care duties amongst married youths compared to single youths. In contrast, the final logistic regression results validate the above statement. Married youths have a positive and a significant coefficient value of 1.07 at $1 \%$ level of significance. This suggests that, being a married youth in comparison to an unmarried youth raises the log odds of becoming a NEET by 1.07. In contrast, as odds ratios are considered, the probability of becoming a NEET is increased by $91.7 \%$, amongst married youth compared to the youths who have never married.

Literature in this direction spotlights the significance of residential sector as a major determinant of youth NEET. Academicians and researchers namely, Furlong [5], McGuinness and Kelly [7], Ranzani and Rosati [9], Bacher et al, [1] and Susan li [13] intensified the greater importance of residential sector in determining the NEET status amongst youths. According to the results of the empirical model, residential sector has acted as a significant determinant of the NEET status among Sri Lankan youths.

Urban sector as the reference residential sector has been omitted from the model in order to get rid of the dummy variable trap. Rural sector indicates a positive as well as significant coefficient of 0.3 under $1 \%$ level of significance, propounding that for youth, living in the rural areas increase the log odds of being NEET by 0.3 . In contrast, the respective odds ratio states that likelihood of becoming a youth NEET is increased by $35.5 \%$ among youths who live in rural areas compared to youths who live in urban areas. Moreover, this likelihood of becoming a youth NEET is increased by $37.1 \%$ among youth who live in estate sector compared to youth who live in urbanized areas. This result highlights the fact that more rural the residential area of a youth, more likely for them to become NEET in Sri Lanka. Generally, urban sector has well established educational and labour market opportunities compared to rural and estate sectors, creating a sectoral gap with regards to NEET status of youth. According to Susan li [13], the prevalence of unpaid family work in rural areas and greater household labour earnings in urban areas caused the likelihood of becoming NEET amongst youths who reside in rural areas.

\section{Conclusions}

This research found that Sri Lanka has a significantly high youth NEET rate of $25.8 \%$ in 2015, which is unsatisfactory to the Sri Lankan labour market. This raises the labour market vulnerability with regards to youth population in the country. In contrast, by gender, female youth NEET rate is higher than male youth, indicating a gender-gap with respect to youth NEET. Hence, lack of young female engagement in labour market, education and training, fabricates undesired outcomes in regard to future labour market in Sri Lanka. Moreover, regression inferences validated a gender-gap with respect to youth NEET by perceiving the fact that, a female is 2.68 times more likely to become a NEET compared to a male in Sri Lanka.

The research also found the significant NEET disparities among youths by the residential sector including the provinces and districts. The youth NEET is relatively high among youths who live in estate and rural areas in Sri Lanka. In contrast, this finding is same for the provinces and districts located in rural areas. This finding could be justified due to the availability of developed infrastructure facilities, well established educational and labour market opportunities in urbanised areas in Sri Lanka.

The study found a positive relationship between the age of the youth and youth's likelihood of becoming NEET within the age group of 15 to 24 . Hence, one-year increase in age increases the odds of becoming NEET by $21 \%$. Besides, this relationship between the age of the youth and that youth's likelihood of becoming NEET exhibits an upward trend in being NEET as age increases in the respective age group. More importantly, there exists a U-shaped curve for youth NEET with the level of education. This U-shaped youth NEET curve indicates that the youth NEET rate is high at lower level of education as well at higher level of education. It is very much obvious that youth NEET rate is high among unschooled due to lack of literacy and potential leading to dearth of labour market and further education, training opportunities. Yet, the fact that youth NEET rate is high among youths who are at the highest education level, adversely affects the future of Sri Lankan labour market, since youth NEET is high among population who have achieved a high level of human development.

Moreover, the highest youth NEET rates recorded from the youths who are married and widowed, while the lowest 
is recorded from the youth who have never married. Hence, marital status has acted as a significant determinant of youth NEET in Sri Lanka, since the probability of becoming NEET is greater amongst married youth compared to the youths who have never married. Additionally, the study also found youth NEET differences among different ethnic groups. The lowest NEET rate exists among Burger youths while the highest is recorded from Sri Lankan Muslims. This might be due to the fact that some Muslim cultural norms act as constraints for Muslim women in participating to educational, training and labour market opportunities. Though, the highest youth NEET rate exists among Islam youths and the lowest among Buddhists, religion has not been identified as a significant determinant of youth NEET in Sri Lanka by the empirical model.

\section{Policy Recommendations}

Current active labour market and welfare policy in Sri Lanka does not focus its attention towards youth NEET in Sri Lanka, since youth NEET is a novel concept to the Sri Lankan labour market and welfare policy. Hence, this study and further research in this area would alert the policy makers to draw more emphasis in this direction. The study found that youths who reside in rural and estate sectors are more vulnerable to becoming a NEET due to the unavailability of required resources. So that, policies should focus on implementing programmes that would facilitate the necessary infrastructure facilities pertinent to more developed educational, training and labour market opportunities in those areas in Sri Lanka. Since, the female NEET rate is relatively higher, empowerment of young women should be established through policy reforms. Thus, educational policy reforms and public awareness programmes should be imposed to alter the ethnic, cultural norms which obstruct the greater inclusion of females in education, training and labour market. Youths with no schooling recorded the highest NEET prevalence. This finding questions the existence of compulsory education policy in Sri Lanka. Hence, early warning systems should be introduced to provide early identification of young people who may be at risk of becoming NEET or dropping out of education.[19]

Furthermore, youth NEET rate tends to increase among youths who attained a higher educational level. This may be due to the fact though they are well-educated, they might not have the skills and attitudes anticipated by the practical labour market. Hence, higher education system should be more labour markets oriented with the additional focus on developing soft skills amongst undergraduates. Moreover, the respective authorities should intervene to the labour market, educational and training procedures in the presence of racial or gender discrimination to safeguard Sri Lankan youths' labour market and educational rights irrespective of their gender and ethnicity.

\section{Appendix}

Table 11. Logistic Regression Results (Coefficients)

\begin{tabular}{cccc}
\hline & Model (1) & Model (2) & Model (3) \\
\hline Age & $0.256^{* * *}$ & $0.194^{* * *}$ & $0.195^{* * *}$ \\
& $(30.21)$ & $(20.54)$ & $(20.59)$ \\
\hline Male = (Reference Category) & Gender & & \\
Female & & & \\
& $1.155^{* * *}$ & $0.989^{* * *}$ & $0.987^{* * *}$ \\
& $(23.90)$ & $(19.76)$ & $(19.71)$ \\
\hline
\end{tabular}

Level of Education

No Schooling $=$ (Reference Category)

\begin{tabular}{cccc} 
Grade 5 and Below & $-2.115^{* * *}$ & $-2.279^{* * *}$ & $-2.280^{* * *}$ \\
& $(-5.24)$ & $(-5.70)$ & $(-5.70)$ \\
\hline Grade 6-10 & $-2.653^{* * *}$ & $-2.798^{* * *}$ & $-2.791^{* * *}$ \\
& $(-7.14)$ & $(-7.64)$ & $(-7.63)$ \\
\hline G.C.E. (O/L) & $-3.117^{* * *}$ & $-3.200^{* * *}$ & $-3.176^{* * *}$ \\
& $(-8.32)$ & $(-8.66)$ & $(-8.60)$ \\
\hline G.C.E.(A/L) & $-3.444^{* * *}$ & $-3.280^{* * *}$ & $-3.257^{* * *}$ \\
& $(-9.22)$ & $(-8.91)$ & $(-8.86)$ \\
\hline Degree and Above & $-3.638^{* * *}$ & $-3.424 * * *$ & $-3.368^{* * *}$ \\
& $(-7.49)$ & $(-7.04)$ & $(-6.92)$ \\
\hline
\end{tabular}

Ethnic Group 


\begin{tabular}{ccc}
\hline Sinhalese $=$ (Reference Category $)$ & & \\
SL Tamil & $0.269^{*}$ & $0.259^{*}$ \\
& $(1.73)$ & $(1.67)$ \\
\hline In Tamil & $0.352^{*}$ & 0.306 \\
& $(1.88)$ & $(1.44)$ \\
\hline SL Moor & 0.734 & 0.687 \\
& $(1.43)$ & $(1.34)$ \\
\hline Malay & 0.0464 & 0.139 \\
& $(0.07)$ & $(0.21)$ \\
\hline Burger & -0.494 & -0.446 \\
& $(-0.61)$ & $(-0.56)$ \\
\hline Other & -0.379 & -0.204 \\
& $(-0.27)$ & $(-0.15)$ \\
\hline
\end{tabular}

\begin{tabular}{|c|c|c|c|}
\hline $\begin{array}{c}\text { Religion } \\
\text { Buddhist }=(\text { Reference } \mathrm{C}\end{array}$ & & & \\
\hline \multirow[t]{2}{*}{ Hindu } & & -0.131 & -0.105 \\
\hline & & $(-0.79)$ & $(-0.63)$ \\
\hline \multirow[t]{2}{*}{ Muslim } & & -0.159 & -0.0468 \\
\hline & & $(-0.31)$ & $(-0.09)$ \\
\hline \multirow[t]{2}{*}{ Catholic } & & -0.0524 & 0.0154 \\
\hline & & $(-0.45)$ & $(0.13)$ \\
\hline \multicolumn{4}{|l|}{ Marital Status } \\
\hline \multicolumn{4}{|c|}{ Never Married= (Reference Category) } \\
\hline \multirow[t]{3}{*}{ Married } & & $1.073^{* * *}$ & $1.071^{* * *}$ \\
\hline & Model (1) & Model (2) & Model (3) \\
\hline & & $(16.19)$ & $(16.13)$ \\
\hline \multirow[t]{2}{*}{ Widowed } & & 0.867 & 0.839 \\
\hline & & $(1.56)$ & $(1.52)$ \\
\hline \multirow[t]{2}{*}{ Divorced } & & 0.479 & 0.525 \\
\hline & & $(0.74)$ & $(0.81)$ \\
\hline \multirow[t]{2}{*}{ Separated } & & -0.0549 & -0.0688 \\
\hline & & $(-0.13)$ & $(-0.17)$ \\
\hline \multicolumn{4}{|c|}{ Residential Sector } \\
\hline \multicolumn{4}{|c|}{ Urban = (Reference Category) } \\
\hline \multirow[t]{2}{*}{ Rural } & & & $0.304^{* * *}$ \\
\hline & & & $(4.48)$ \\
\hline \multirow[t]{2}{*}{ Estate } & & & $0.316^{* *}$ \\
\hline & & & $(1.98)$ \\
\hline \multirow[t]{2}{*}{ Constant } & $-3.772 * * *$ & $-2.713^{* * *}$ & $-3.018 * * *$ \\
\hline & $(-9.39)$ & $(-6.69)$ & $(-7.34)$ \\
\hline $\mathrm{N}$ & 11710 & 11708 & 11708 \\
\hline Prob > chi2 & $0.0000^{* * *}$ & $0.0000 * * *$ & $0.0000^{* * *}$ \\
\hline Pseudo R2 & 0.1268 & 0.1518 & 0.1533 \\
\hline
\end{tabular}

Note: "t statistics in parentheses"; ${ }^{*} \mathrm{p}<0.1,{ }^{* *} \mathrm{p}<0.05,{ }^{* * *} \mathrm{p}<0.01$ 
Table 12. Logistic Regression Results (Odds Ratios)

\begin{tabular}{cccc}
\hline & Model (1) & Model (2) & Model (3) \\
\hline Age & $1.29^{* * *}$ & $1.213^{* * *}$ & $1.214^{* * *}$ \\
& $(30.21)$ & $(20.54)$ & $(20.59)$ \\
\hline Gender & & & \\
Male = (Reference Category) & & & \\
Female & $3.173^{* * *}$ & $2.688^{* * *}$ & $2.684^{* * *}$ \\
& $(23.90)$ & $(19.76)$ & $(19.71)$ \\
\hline
\end{tabular}

Level of Education

No Schooling $=$ (Reference Category $)$

\begin{tabular}{cccc} 
Grade 5 and Below & $0.120^{* * *}$ & $0.102^{* * *}$ & $0.102^{* * *}$ \\
& $(-5.24)$ & $(-5.70)$ & $(-5.70)$ \\
\hline Grade 6-10 & $0.070^{* * *}$ & $0.060^{* * *}$ & $0.061^{* * *}$ \\
& $(-7.14)$ & $(-7.64)$ & $(-7.63)$ \\
\hline G.C.E. (O/L) & $0.044^{* * *}$ & $0.040^{* * *}$ & $0.041^{* * *}$ \\
& $(-8.32)$ & $(-8.66)$ & $(-8.60)$ \\
\hline G.C.E.(A/L) & $0.031^{* * *}$ & $0.037 * * *$ & $0.038^{* * *}$ \\
& $(-9.22)$ & $(-8.91)$ & $(-8.86)$ \\
\hline Degree and Above & $0.026 * * *$ & $0.032^{* * *}$ & $0.344^{* * *}$ \\
& $(-9.39)$ & $(-7.04)$ & $(-6.92)$ \\
\hline
\end{tabular}

Ethnic Group

Sinhalese $=($ Reference Category $)$

\begin{tabular}{ccc} 
SL Tamil & $1.308^{*}$ & $1.296^{*}$ \\
& $(1.73)$ & $(1.67)$ \\
\hline In Tamil & $1.421^{*}$ & 1.357 \\
& $(1.88)$ & $(1.44)$ \\
\hline SL Moor & 2.082 & 1.987 \\
& $(1.43)$ & $(1.34)$ \\
\hline Malay & 1.047 & 1.149 \\
\hline Burger & $(0.07)$ & $0.21)$ \\
\hline Other & 0.610 & 0.639 \\
& $(-0.61)$ & 0.815 \\
\hline Religion & 0.684 & $(-0.15)$ \\
\hline Buddhist $=$ (Reference Category) & $(-0.27)$ & \\
Hindu & & $(0.13)$ \\
\hline Muslim & & $(-0.09)$ \\
\hline & 0.9645 \\
\hline
\end{tabular}




\begin{tabular}{|c|c|c|c|}
\hline \multicolumn{4}{|c|}{$\begin{array}{c}\text { Marital Status } \\
\text { Never Married= (Reference Category) }\end{array}$} \\
\hline \multirow[t]{2}{*}{ Married } & & $2.924 * * *$ & $2.917 * * *$ \\
\hline & & (16.19) & (16.13) \\
\hline \multirow[t]{2}{*}{ Widowed } & & 2.379 & 2.313 \\
\hline & & $(1.56)$ & $(1.52)$ \\
\hline \multirow[t]{2}{*}{ Divorced } & & 1.614 & 1.691 \\
\hline & & $(0.74)$ & $(0.81)$ \\
\hline \multirow[t]{2}{*}{ Separated } & & 0.946 & 0.933 \\
\hline & & $(-0.13)$ & $(-0.17)$ \\
\hline \multicolumn{4}{|c|}{ Residential Sector } \\
\hline \multicolumn{4}{|c|}{ Urban = (Reference Category) } \\
\hline \multirow[t]{2}{*}{ Rural } & & & $1.355^{* * *}$ \\
\hline & & & $(4.48)$ \\
\hline \multirow[t]{2}{*}{ Estate } & & & $1.371^{* *}$ \\
\hline & & & (1.98) \\
\hline Constant & $0.023 * * *$ & $0.066^{* * *}$ & $0.048^{* * *}$ \\
\hline $\mathrm{N}$ & 11710 & 11708 & 11708 \\
\hline Prob > chi2 & $0.0000^{* * *}$ & $0.0000^{* * *}$ & $0.0000^{* * *}$ \\
\hline Pseudo R2 & 0.1268 & 0.1518 & 0.1533 \\
\hline
\end{tabular}

Note: "t statistics in parentheses"; ${ }^{*} \mathrm{p}<0.1,{ }^{* *} \mathrm{p}<0.05,{ }^{* * *} \mathrm{p}<0.01$

\section{REFERENCES}

[1] Bacher J, Tamesberger D, Leitgöb H, Lankmayer T. Not in Education, Employment or Training: Causes, Characteristics of NEET-affected Youth and Exit Strategies in Austria: Working Paper [Internet]. 2014 [cited 2016 Dec 9]: 1-29. Available from: www.jku.at/soz/content/e222092/ e245158/NEET_Austria_2014_final-l_ger.pdf

[2] Department of Census and Statistics. Sri Lanka Labour Force Survey Annual Report - 2015. Battaramulla: Department of Census and Statistics; 2015.

[3] Elder S. What does NEETs mean and why is the concept so easily misinterpreted? ILO-Technical Brief No 1 [Internet]. 2015 [cited 2017 Dec 15]: 1-16. Available from: www.ilo.org/wcmsp5/groups/public/@dgreports/@dcomm/ .../wcms_343153.pdf

[4] Social Exclusion Unit. Bridging the Gap: New Opportunities for 16-18 Year Olds Not in Employment, Education or Training [Internet]. 1999 [cited 2017 Feb 17]. Available from:dera.ioe.ac.uk/15119/2/bridging-the-gap.p $d f$

[5] Furlong A. Not a Very NEET Solution: Representing Problematic Labour Market Transitions Among Early School-Leavers. Work, Employment \& Society [Internet]. 2006 [cited 2016 Dec 15]; 20(3): 553-569. Available from: http://www.jstor.org/stable/23749087

[6] Yuji G. Jobless Youths and the NEET Problem in Japan. Social Science Japan [Internet]. 2007 [cited 2016 Dec 15]; 10(1): 23-40. Available from: http://citeseerx.ist.psu.edu/vi ewdoc/download?doi=10.1.1.529.9414\&rep=rep1\&type $=$ $p d f$

[7] McGuinness S. Kelly E. The Impact of the Recession on the Structure and Labour Market Success of Young NEET Individuals in Ireland. ESRI Working Paper [Internet]. 2013 [cited 2016 Dec 15]: 1-17 Available from: at: https://www.ceps.eu/.../ENEPRI\%20CEPS\%20\%20DG\%2 Demploy\%20Conference\%2...

[8] Kovrova I. Lyon S. NEET Youth Dynamics in Indonesia and Brazil: A Cohort Analysis. Working Paper [Internet]. 2013 [cited 2016 Dec 15]: 1-26. Available from: siteresources.worldbank.org/.../NEET_Youth_cohort_effec ts_Indonesia\&Brazil.pdf

[9] Ranzani M. Rosati F. The NEET trap: A dynamic analysis for Mexico. UCW Working Paper [Internet]. 2013 [cited 2016 Dec 15]. Available at: www.ucw-project.org/.../Youth _Empl_NEET_TRAP_MEXICO20130328_160614.p...

[10] Samoilenko A. Carter K. Economic Outcomes of Youth not in Education, Employment or Training (NEET). New Zealand Treasury Working Paper [Internet]. 2015 [cited 2016 Dec 15]; 15(1): 1-34. Available from: https://ideas.repec.org/p/nzt/nztwps/15-01.html

[11] Feng Z. Everington D. Ralston K. Dibben C. Raab G. Graham E. Consequences, risk factors and geography of 
young people not in education, employment or training (NEET). Children, Education and Skills [Internet]. 2015 [cited 2016 Dec 9]. Available from: www.gov.scot/Publications/2015/10/2258

[12] Mendolia S. Walker I. Do NEETs Need Grit? IZA Discussion Paper [Internet]. 2014 [cited 2016 Dec 9]; 8740: 1-35. Available from: ftp.iza.org/dp8740.pdf

[13] Susan li Z. Understanding the NEET in Turkey. Eurasian Journal of Economics and Finance [Internet]. 2016 [cited 2016 Dec 9]; 42(2): 42-57. Available from: www.eurasianpublications.com

[14] Wooldridge J. Introductory Econometrics: A Modern Approach, 4th ed. Delhi: Cengage Learning; 2009.

[15] Gujarati D. Basic Econometrics: 4th ed. Delhi: Tata McGraw Hill Education Private Limited; 2007.

[16] Perera A. Women's Labour Force Participation in Sri Lanka: An Inquiry into the Key Social and Cultural Constraints
[Internet]. 2017 [cited 2017 Mar 3]. Available from: http://www.ips.lk/talkingeconomics/

[17] Yan L. Sun Y. Boivin M. Kwon P. Li Y. Revealing Facts and Avoiding Biases: A Review of Several Common Problems in Statistical Analyses of Epidemiological Data. Front Public Health [Internet]. 2016 [cited 2017 Mar 3]; 4(207). Available from:https://www.ncbi.nlm.nih.gov/pmc /articles/PMC5053988/

[18] Bartlett J. R Squared In Logistic Regression [Internet]. 2014 [cited 2017 Mar 3]. Available from: http://thestatsgeek.com/2014/02/08/r-squared-in-logistic-r egression/

[19] Young Women's Trust. NEETs and Gender [Internet]. 2014 [cited 2017 Feb 17]. Available from: http://www.youngwo menstrust.org/assets/0000/0665/Scarred_for_Life-Literatu re_Review-September_2014.pdf 